Reexploring Children's Illness Uncertainty and Management Experiences with Female Japanese Cancer Survivors

\author{
Yu Ishii \\ Toshihiko Endo \\ University of Tokyo
}

Author Note
Yu Ishii iD https://orcid.org/0000-0002-1614-9235

Correspondence concerning this article should be addressed to $\mathrm{Yu}$ Ishii, Graduate School of Education, University of Tokyo, 7-3-1 Hongo, Bunkyo-ku, Tokyo,113-0033, Japan.

Email: yuishii@p.u-tokyo.ac.jp 


\title{
CHILDREN'S IU AND MANAGEMENT
}

Reexploring Children's Illness Uncertainty and Management Experiences with Female Japanese Cancer Survivors

\begin{abstract}
The purpose of our study was to examine what illness uncertainties (IU) children experience now and how they manage it, with the aim to use the findings to construct long-term, comprehensive developmental care for children with illness. We conducted interviews with six Japanese adolescent cancer survivors, all recruited from the same hospital in Tokyo, Japan. Using directed content analysis, we first present new aspects of children's IU, the first one being the IU of hospitalization itself, which may be frequently experienced by younger children. We also present the necessity to distinguish and examine IU with and without answers, and discuss the uncertainty of "why me?" Also, in terms of IU management, we present the informative value "role models" have in terms of reducing IU, and depict how uncertainty acceptance might be a new goal a patient aims to achieve.
\end{abstract}

Keywords: Illness uncertainty, uncertainty management, pediatric illness, pediatric cancer, directed content analysis 


\section{Introduction}

In Japan, the long-term survival rate of childhood cancer and other illness that was once considered as fatal has improved dramatically with the significant advance of medical treatment (e.g., Takahashi et al., 2018). However, even now, psychological care provided in hospitals for children are aimed primarily to reduce the distress children are experiencing at that moment, and despite the strong demand (Omata, 2018), no care has been developed with a long-term developmental perspective in mind. In this study, we focused on illness uncertainty (IU) as a potential key concept for constructing long-term, comprehensive developmental care for children with illness.

IU is defined by Mishel (1988) as "the inability to determine the meaning of illnessrelated events when a patient cannot structure or categorize an event because of insufficient cues." The concept has attracted great attention from researchers who seek to improve the quality-of-life of patients with various illness. Previous research has dealt with patients of wide age range worldwide and it is now known that higher levels of IU directly correlate with higher levels of depression, anxiety, and poorer quality of life (e.g., Clayton, Mishel, \& Belyea, 2006; Giurgescu, Penckofer, Maurer, \& Bryant, 2006; Northouse, Dorris, \& Charron-Moore, 1995; Sammarco, 2001; Szulczewski, Mullins, Bidwell, Eddington, \& Pai, 2017b; White et al., 2005).

No doubt, the development of the Child Uncertainty in Illness Scale (CUIS; Mullins \& Hartman, 1995; Pai et al., 2007) and the Uncertainty Scale for Kids (USK; Stewart, Lynn, \& Mishel, 2010) have facilitated research in the context of pediatric illness. CUIS was developed based on Mishel's theory and is a modified version of MUIS-Community Form (Mishel, 1997), whereas USK was developed based on the study Stewart (2003) conducted on 11 children between the ages of nine and 12 years with cancer, to explore the importance of uncertainty to their experiences with cancer and its treatment. Similar to that of adult research findings, Szulczewski et al.'s (2017) meta-analysis revealed that children's uncertainty is associated with their general psychological functioning, anxiety, depression, and psychological distress independently. 


\section{CHILDREN'S IU AND MANAGEMENT}

Additionally, a recent research conducted based on the findings from the time perspective research (e.g., Lewin, 1942; Nuttin \& Lens, 1985), presented the possibility that IU may have a significant influence on children's future time perspective, thus having a long-term developmental effect on the child (Ishii, 2018). The study pointed out that not being able to "determine the meaning of an illness-related event" (Mishel. 1988), or having "an incomplete or insufficient cognitive schema, or internal representation, of the illness" (Stewart, 2003), may result in children not being able to construct a more adaptive future life perspective, i.e., a more extended, valued, connected and an expectation versus fantasy future time perspective (Andriessen, Phalet, \& Lens, 2006; Oettingen \& Mayer, 2002). This is because future time perspective is constructed upon the individual's appraisal of the self (for reviews on self-concept and self-knowledge; Cross \& Markus, 1994; Markus, 1983) and is considered crucial for one to have a sense of control over his/her life for an adaptive future time perspective to be constructed (Husman \& Shell, 2008), which IU may prevent one from constructing. The study reported that not all, but some IU, including IU experienced in the social aspect of the illness (e.g., the possibility of getting discriminated) may affect the child's future planning, thus suggesting management of IU may benefit children in the long run.

However, previous research has not been conducted with long-term care in mind, thus with this perspective, new themes may emerge. It is also worth noting that with the significant advance in medicine, what children today experience in hospitals may well differ from what was used to be experienced 20 years ago. Therefore, the purpose of the present study was to reconsider the concept of children's IU with the aim to construct long-term, comprehensive care for children with illness. Specifically, we aimed to examine what uncertainties children experience and how they reduce or manage those uncertainties.

In achieving this aim, we decided to approach adolescents who have experienced pediatric cancer and have finished their treatments. Pediatric IU is an understudied topic in Japan, and to our knowledge, this is the first study to focus on pediatric IU other than Ishii (2018), who have examined survivors of different pediatric illnesses such as heart disease and cancer in Japan. In this situation, cancer survivors would be the best subject, since 


\section{CHILDREN'S IU AND MANAGEMENT}

cancer is one of the illnesses that have been studied intensely in pediatric IU research (Szulczewski et al., 2017), therefore allowing us to deepen our analysis by comparing with previous findings.

\section{Method}

\section{Methodological Approach}

Considering the ample findings and theories already reported on IU, we thought it best to apply directed content analysis for this research. Directed content analysis is appropriate to use when theories already exist but prior theories and research about the phenomenon is incomplete and could benefit from further description, with the goal "to validate or extend conceptually a theoretical framework or theory" (Hsieh \& Shannon, 2005, p. 1281). In the present study, we aimed to explore how the framework constructed by previous studies, such as Mishel (1988), Brashers et al. (2003) could be refined or extended with new data. Thus, as explained below, we constructed our interview guide and conducted our analysis accordingly.

\section{Study Participants}

Head teacher of the in-hospital class at a university of hospital ( $Z$ hospital) in Tokyo, Japan, where the first author (FA) volunteered for a year, agreed to recruit participants for the present study. Inclusion criteria included being treated at the hospital with pediatric cancer, being an adolescent, fluent in Japanese, cognitively able to participate in the interview (as indicated by the parent). The head teacher attempted to call the parent of every eligible former student and briefly explained about the study, and if the parent agreed to let their child know about the research, they told the child the FA's contact information. If the child agreed to participate, he/she contacted the FA via email or text, and the FA explained about the study to the potential participant. Of the six females who consented to participate in the study, one canceled once due to the possibility of recurrence but found out later that it was not a relapse, and was once again included in the study on her request. 


\section{Instruments and Data Collection}

In 2019, the FA conducted semi-structured, in-person interviews in a private conference room at the university or off-site, as per participant preference. The participants were told in advance that the interview would last about one to two hours, which lasted 53 to 171 minutes $(M=92$ minutes). When starting the interview, the FA provided information about the study once again and obtained written consent.

Throughout the interview, the FA used an interview guide so each data would be comparable and so it would prevent the FA from forgetting any questions. The interview guide was developed referring to Smith (1995). As descripted in Hsieh \& Shannon (2005), it was constructed so that broader questions were placed in the first half (e.g., about the illness and the treatment in general), and more specific questions were placed in the later half (e.g., about the experienced uncertainties). Of note, however, in order for the participants to relax and talk in a more natural way as possible, the interview guide was not strictly adhered and was looked at only briefly for guidance. Also, especially when asking about the experience of illness uncertainty, the FA asked interpretive questions (Merriam, 1998 ) in order to prevent misinterpretation of the data.

All interviews were audio-recorded with participant consent. Field notes and memos were made during and immediately after each interview to capture contextual observations.

\section{Analysis}

Normally, when conducting a directed content analysis, a categorization matrix is developed based on earlier works and coding is done based on this matrix (Elo \& Kyngäs, 2008). However, as Hsieh \& Shannon (2008) points out, we feared that this approach may lead us to unconsciously skew the data in some way as we try to fit the data into preexisting categories/codes. So as not to distort the data in anyway, we coded the data with the codes we defined from the data, and cross-referenced it with the existing literature after all the coding and categorization were done.

First, data from all interviews were transcribed verbatim and all transcriptions were read repeatedly and carefully to gain a deep understanding. Then, we extracted all 


\section{CHILDREN'S IU AND MANAGEMENT}

transcriptions that fell under the definition "the person is unable to construct the meaning of an illness related event of her/his self or another, and is aware of the state," a definition we developed to capture IU ( The extracts included phrases such as "I didn't know," "wasn't sure," "worried," "why," and "until when." Then we coded each phrase paying great attention to the context. After coding was done, the codes were compared with previous research, especially Mishel (1988), Brashers et al. (2003), and Han, Klein, \& Arora (2011). New and emergent themes were identified at this stage by cross referencing the codes with the data, and with additional review of the literature.

These data are not publicly available due to their containing information that could compromise the privacy of participants. Note that we analyzed the data first and translated that Japanese into English when writing this article. All translation was done by a bilingual translator and validation was done by the FA.

\section{Ethics}

This study protocol was reviewed and approved by the ethics review committee of the University of Tokyo (13-147), and all participants provided informed, written consent prior to study participation.

\section{Findings}

In order to understand the phenomenon of children's IU, when analyzing, we took contexts very seriously, including by whom and in what context the particular statement was made in. Therefore, rather than summarizing the characteristic of the participants, we report here the background of each participants, using pseudonyms and excluding personally identifiable information (Table 1, Table 2). 
Table 1

Characteristics of Participants

\begin{tabular}{llcc}
\hline Name & \multicolumn{1}{c}{ Experienced cancer } & $\begin{array}{c}\text { Age at diagnosis } \\
\& \text { treatment }\end{array}$ & $\begin{array}{c}\text { Age at } \\
\text { interview }\end{array}$ \\
\hline Mary & $\begin{array}{l}\text { Germ cell tumor / } \\
\text { Kidney cancer / Ischium tumor }\end{array}$ & 13,14 & 21 \\
& Retinoblastoma / & & \\
Sarah & Osteosarcoma (twice)/ leukemia & $0,8,12$ & 17 \\
Tiffany & Acute myeloid leukemia (three times) & $10,11,12$ & 20 \\
Kate & Acute myeloid leukemia (twice) & 16,18 & 20 \\
Melanie & Acute lymphocytic leukemia & 13 & 22 \\
Jasmine & Acute lymphocytic leukemia & 11 & 21 \\
\hline
\end{tabular}

Also, so as to allow transparency and enable readers to critically appraise our findings and discussions, rather than listing the uncertainties and management strategies we found from our interviews, we decided to present these findings within each person's episode. Especially since cancer treatments differ greatly between countries and ages, we believed this would provide readers the information to help them see the context and consider the validity of the present study. Therefore, in this section, we will present each person's interview in brief, while presenting the uncertainties and management episodes, together with the statements that characterizes the person in detail.

Table 2

Experienced Uncertainties

\begin{tabular}{|c|c|c|c|c|}
\hline \multirow[b]{2}{*}{ Name } & \multicolumn{2}{|c|}{$\begin{array}{l}\text { Uncertainties told while explaining about the illness } \\
\text { (Answers to question 1) }\end{array}$} & \multicolumn{2}{|c|}{$\begin{array}{l}\text { Uncertainties told as an answer to the IU question } \\
\text { (Answers to question 2) }\end{array}$} \\
\hline & Experienced period & Experienced uncertainties & Experienced period & Experienced uncertainties \\
\hline Mary & - & none & - & none \\
\hline Sarah & $\begin{array}{l}\text { Before second surgery } \\
\text { Before diagnosed with } 4 \text { th cancer }\end{array}$ & $\begin{array}{l}\text { Success/failure of the treatment } \\
\text { "why me?" }\end{array}$ & - & none \\
\hline Tiffany & $\begin{array}{l}\text { During third treatment } \\
\text { Now (with late side effects) }\end{array}$ & $\begin{array}{l}\text { Impact/side effect of treatment } \\
\text { "why me?" }\end{array}$ & - & none \\
\hline Kate & - & none & $\begin{array}{l}\text { At diagnosis } \\
\text { At diagnosis } \\
\text { Treatment beginning - now } \\
\text { Start of treatment }\end{array}$ & $\begin{array}{l}\text { Prognosis (death, recurrence) } \\
\text { "why me?" } \\
\text { Impact/side effect of treatment } \\
\text { Safety of the treatment }\end{array}$ \\
\hline Melanie & At diagnosis & "why me?" & $\begin{array}{l}\text { Before hospital discharge } \\
\text { After hospital discharge }\end{array}$ & $\begin{array}{l}\text { Social reaction to the illness } \\
\text { Prognosis (death, recurrence) }\end{array}$ \\
\hline Jasmine & $\begin{array}{l}\text { When she had a heavy nosebleed } \\
\text { When she had a heavy nosebleed } \\
\text { At diagnosis } \\
\text { At diagnosis } \\
\text { When treatment started } \\
\text { During treatment } \\
\text { After hospitalization }\end{array}$ & $\begin{array}{l}\text { Meaning of symptoms } \\
\text { Correctness of the diagnosis } \\
\text { "why me?" } \\
\text { Prognosis (death) } \\
\text { Good/bad things to do during } \\
\text { treatment } \\
\text { About the treatment } \\
\text { Hospitalization itself }\end{array}$ & $\begin{array}{l}\text { After hospitalization } \\
\text { During hospitalization } \\
\text { During treatment } \\
\text { During treatment } \\
\text { During treatment } \\
\text { During hospitalization - } \\
\text { several years after }\end{array}$ & $\begin{array}{l}\text { Structure of the hospital } \\
\text { How to interact with hospital staff } \\
\text { Meaning/necessity of treatment } \\
\text { Duration of hospitalization } \\
\text { Impact/side effect of treatment } \\
\text { Financial burden on family }\end{array}$ \\
\hline
\end{tabular}


Mary's case. Mary realized something was wrong with her the month after she entered junior high. She had a high fever, and after taking medicine that was prescribed by her primary care doctor who thought the fever was to due constipation, the fever did not go down, so went to a university hospital, where she found out her ovary was at high risk of rupture and had to undergo surgery that day. She says she doesn't remember anything about that day because everything went so fast. After the surgery, she was told that they found a tumor in her kidney as well. She had experienced pain in her hip before, but had thought the pain was caused from her bad posture, never suspecting it was caused by cancer.

When asked about how she came to know about the details about her illness and treatment, she answered as follows:

I asked them to tell me everything. Also, I sat through all the explanations on the surgery and treatment. You know how data on blood and stuff are all written in alphabet? So there's all these data on a piece of paper, but the doctors at the $\mathrm{Z}$ university explained to me like, this indicates white blood cell levels and its usually around this high but in my case it's this much, and all that. They were so nice. And their explanation was easy to understand [laughs].

When asked if she have had any concerns or uncertainties, she said she have had "none."

I didn't really have any [laughs]. I was allowed to ask questions. They would answer me...Residents are just below 30, close enough to be my older sister, so they would even help me with my studies and tell me about my illness. I'd ask them things like "How long would it be till I can go home?"

This statement indicates that she had experienced IU but was able to resolve them naturally by asking residents who were close age.

Sarah's case. Sarah said they found cancer in both her eyes and had no choice but to remove the right eye, but "was just barely able to leave and treat the left eye with radiation." When she was in second grade, she got second cancer in her bone near her left eye due to the radiation treatment. It was her father who noticed that her left eye was popping out. She said, "we wanted to leave the left eye, so we scrapped off the cancer part 


\section{CHILDREN'S IU AND MANAGEMENT}

of the bone and put the remaining part back inside, but it recurred so we just had to take the whole bone out." As for the fourth cancer, leukemia, she talked about how her nosebleed did not stop on the night of the day she took an entrance exam for junior high school. She had lost her appetite and her joints had hurt for a while, but she thought all of it were caused by the stress of the exam.

In the interview, Sarah spent a lot of time talking about the osteosarcoma.

When I was losing my sight, I guess that was one of the hardest times. Losing sight when I was once able to see was, um, pretty, I don't know, really hard I guess.

She also mentions the concern she had about the second surgery (uncertainty regarding treatment result).

When hearing about my surgery, the first time I would still have an eye left, so I wasn't really that scared. I went to the surgery room laughing saying "See you later!" [laughs]. But, I guess, I didn't really understand what the procedure was about at that time...The second time, I was scared and anxious hearing about the procedure... The hospital ward was not well-lighted, and I couldn't see anything in the dark so, well, I got anxious.

Also, she talked about the "question" she had, saying "before I was diagnosed with leukemia, or maybe after, I was like "why me?" (uncertainty regarding self). She said she never talked about this with anyone, and especially not with her doctor-in-charge, because she felt like he would just lightly say “you're fine, you're fine!" She went on to say "I used to think I got it because my grandpa did too, but it doesn't matter now [laughs]," saying "If I get sick again, all I need to do is treat it again, so I'm good as long as I'm living."

In terms of how she learned about her illness, she said her mom wasn't "the type to hide," and that while she was hospitalized with osteosarcoma or leukemia, her mom told her about the disease and explained details. Thus, regarding the uncertainties she experienced, her answered "I don't think I have had anything I'm uncertain of."

Tiffany's case. Tiffany found out about her leukemia when she was in fourth grade. It was found by a blood test she took based on her parents' suggestion, who thought her lips were too pale. Soon after, she was hospitalized at a children's hospital. 


\section{CHILDREN'S IU AND MANAGEMENT}

In her interview, she talked mostly about her concern about her studies. Stating that since there wasn't an in-hospital school at the children's hospital, she said "I pretty much did my studying by myself." After seven months of anti-cancer drug treatment, she was discharged the following summer, but was hospitalized again at $\mathrm{Z}$ hospital due to recurrence. During this period, she said she not only did anti-cancer drug treatment and radiation therapy, but also had her sister's bone marrow transplanted which was "a full match." However, her cancer once again relapsed, "because the GVHD was not effective enough" in her case. During the next hospitalization, which started when she was in six grade, she had a bone marrow transplant again, on the first day of junior high school.

Tiffany says she heard about the diagnosis the day she was hospitalized. She also heard that she would be hospitalized for a long period and that she would be getting treatments, but says she did not learn about the specifics of the treatments.

I'd only heard that it would make me feel sick. And that my hair would fall out. I didn't ask about how long it would take, or details. I think they did say about how many months. But I don't remember asking about it myself, really.

When the FA asked her about the uncertainties she experienced, she said "I wasn't anxious when I was hospitalized because I knew I would be able to get back (to school)." However, she also mentioned the following, indicating she had experienced uncertainties regarding treatment.

But once, there was a time I felt sick for pretty long (during a round of anti-cancer drug treatment). I wondered then how it was before. Like, had I always been like this?

Also, she talked about how she has been dealing with the late side effects of the treatment she received, and how she has recently been questioning why she became sick (uncertainty regarding self).

I'm having problems with my eyes and am taking medication (recently). It has nothing to do with my sickness, but I've been to the ophthalmologist a lot. So I do sometimes wonder why I became sick, recently. 


\section{CHILDREN'S IU AND MANAGEMENT}

Kate's case. Right at the very start of the interview, Kate started explaining about her cancer in detail, saying "I had Acute myeloid leukemia, and the subtype of M0."

When she was 15, she was experiencing strong fatigue and her legs had swollen up. She saw a few physicians and later found out that she had leukemia at $\mathrm{Z}$ hospital. Kate described about her treatments in detail as well.

My treatment, well, it was my first so we took it slow. I think we started off with a week or something. One week with an anti-cancer drug which everyone takes called Cytarabine, and, another colored anti-cancer drug. It was blue and looked unpleasant. That made me feel really sick for the first time.

So, I had five rounds of anti-cancer treatment. I did one week, and then I got a month off. The second round was orange instead of blue, and I didn't get sick. I was fine the second, third, fourth and fifth round, but around the third round, oh, no, it was the first. The first time, I had a bone marrow aspiration, and they told me that the drug wasn't working on the bad cells so I needed a transplant, but we went ahead with the five rounds. Plus, the transplant, and then radiation treatment. Also there was one type of anti-cancer drug different from the usual kind, which flowed with double the speed. Um....I think I had radiation therapy three times, maybe? Three times. Twice a day, three times, I think. And I had the transplant on October 30th, Halloween.

After all the treatment was done and she was discharged, the cancer relapsed. She found this out at a follow-up check and she chose to change the hospital to where her doctor-in-charge had relocated to. Whenever she had treatment, one week before it, she was called in with her mother to hear the details and "signed consent forms if there were any."

When asked about the uncertainties she experienced, she first mentioned the possibility of death (uncertainty of the prognosis), saying "when I first heard about it, I was worried that it was the sort of sickness people die from." She then continued to talk about an uncertainty regarding the possibility of infertility due to the treatment, which she is still experiencing today (uncertainty of side effect of treatment). 


\section{CHILDREN'S IU AND MANAGEMENT}

Another thing I was worried about was, when I was given radiation therapy, they told me I would have less chance of getting pregnant. I worried about becoming unable to bear a child...

Regarding this uncertainty, she asked the doctor, who told her that "even though they say that radiation therapy might affect fertility, I've seen more people who got pregnant." However, she continued by saying,

But I'm taking medicine to induce menstruation, I need medicine to induce menstruation, I'm worried if I'm really gonna be able to get pregnant.

She also mentioned how she wondered why the cancer came to her (uncertainty regarding self).

A year before I was hospitalized, when I was in ninth grade, my classmate's brother had gotten leukemia and died. So, I was scared....I wondered why it came to me.

When she was experiencing uncertainties about the prognosis and why she had to experience the illness, she had an interaction with her doctor-in-charge, which made the uncertainties less of a concern for Kate.

When I talked to my doctor, he looked me straight in the eye and said "I'll do my best so that you can become a wonderful adult, so let's do our best together." That's when I thought, wow, he's a great doctor, maybe I might be alright. (Kate)

Finally, she talked about her concern about the safety of the blood transfusion (uncertainty of the safety of a treatment).

When I had the blood transfusion, right at the time I was in the hospital, there was talk about how the blood for the transfusion...the person who had donated the blood had HIV and the person who received it had gotten it. I thought "What? It isn't safe?".

She dealt with this by "asking the doctor, writing down everything he answered".

Melanie's case. Melanie had played basketball since she was in elementary school, but after she started junior high, she realized her physical strength had dwindled significantly. Her primary doctor suspected Osgood-Schlatter disease but her basketball 


\section{CHILDREN'S IU AND MANAGEMENT}

coach, who recently had his wife diagnosed with cancer, recommended her to go to a bigger hospital.

By the time she was at the hospital she was barely able to walk, and after some tests, she was transferred to $\mathrm{Z}$ hospital and "had to stay there." The test results came out soon.

A whole bunch of doctors came in (to my hospital room), and while I was wondering what was happening, my dad started crying...So I was convinced something was wrong by the time the doctor, he was the straightforward type, told me. There was no beating around the bush, and he said "You have been diagnosed with ." I wasn't familiar with the details of the disease, but because I had heard of the name on television, tears welled up the second I heard the diagnosis and I thought I was going to die.

It took time for her to accept her situation and she always wore a hat and never wanted to take a bath. However, seeing other children in the same ward slowly changed her mind.

By the time my head started to itch, I was gradually able to accept, and in the end, I was like "Fine, I'm going to go take out all my hair today." My parents persuaded me too. And the other kids, the ones who's been in the hospital for a while, were doing okay, so seeing them be optimistic made me feeling like I just gotta do it.

She also talked about the pamphlet a nurse gave her, which "describes the disease briefly, and how its curable, so we should all fight together to overcome," and also mentioned how she was explained about the treatments from doctors, while also mentioning that she "asked everything she was concerned about."

When asked about the uncertainties she experienced, she first talked about her experience after discharge (uncertainty of prognosis).

We were told that we couldn't be sure that I was fully cured until five years had passed since being discharged from the hospital and treatment. So, my parents were scared for those five years, but I didn't take it seriously at all...Well, I rebelled against my parents and said stuff like "Leave me alone" and "I'm fine!" My parents, crying, I don't think they had planned to, but warned me how this girl or that boy was no longer with us; that I have to be careful or I'd get pneumonia 


\section{CHILDREN'S IU AND MANAGEMENT}

and end up back in the hospital. So I had an image of being hospitalized again as meaning the end, and was scared for a while after being discharged.

She said this uncertainty faded away after five years from discharge.

She also talked about her wig (uncertainty regarding social response).

I wasn't insecure in my environment at the hospital, but after going back to school, I could tell everyone was being extra nice. I hadn't told them about my wig, so that made me insecure and anxious...So there was some talk, like how my hair doesn't flutter in the wind [laughs]. Of course, no one said that to my face, so the wig stayed a rumor.

She found out about this rumor by asking a close friend. The reason she had kept secret about the wig and about her illness to everyone was because her parents suggested not to tell anyone. After moving into senior high school, like her parents, she also strongly felt like "I don't want anyone to know." Entering senior high school, where no one knew her past, enabled her to feel like she had become a "new me."

Jasmine's case. Jasmine found out about her illness when she was in fifth grade. She felt dizziness when her relatives were gathered for a summer festival, and soon after, she had a severe nosebleed. She wondered why she was bleeding so badly (uncertainty regarding symptom), and after she was told that she was bleeding from using too much airconditioning she was concerned about the correctness of the diagnosis (uncertainty regarding diagnosis).

At an otorhinolaryngology clinic she went after, she was suggested to take a blood test. After the result came out, the doctor called her mother to tell her to go to a bigger hospital, and at the $\mathrm{Z}$ hospital, she was told to hospitalize.

Jasmine then talked about the time she was diagnosed, indicating that that was the hardest period for her throughout the experience. She here talks about how she wondered the cancer happened to her (uncertainty regarding self).

About a week after I was hospitalized my family was summoned and explained to

first. That their child had leukemia, and what type it was. After that it was my turn to be told, and I wondered why this happened to me, I couldn't accept it. Yet, I felt my 


\section{CHILDREN'S IU AND MANAGEMENT}

family must be having a harder time so I kept from crying, but the doctor must've noticed; he said it's okay to and tears streamed down. Yeah, that part was a bit hard. Then talk turned to the treatment. Before starting the treatment, they explained I would need to plied with a lot of medicine to fight it, and there will be side effects, but that I could do it.

Around the same time Jasmine was hospitalized, a famous actress in Japan died from leukemia, making her concerned about the possibility of death (uncertainty regarding prognosis).

The doctor told me I would be cured but the possibility of death wasn't zero. Having heard that there were some cases in which patients died gave me something to think about.

Regarding this uncertainty, she indicated that in addition to the explanation from the physicians, the appearance of other children who were hospitalized in the ward with the same illness helped resolve it.

Witnessing various cases (of children with the same disease), and hearing the doctor say that with medical care advancing each year, it is no longer an incurable disease but one that is easy to cure, my worries gradually melted away and I felt relieved, yeah, something like that. (Being in a private room was hard) because you have little information. You don't get to interact with others... Getting sick in 5th grade puts you in a position with little information. You have limited means of gathering information.

Regarding treatment, she mentioned the concern she had when she was placed an arterial catheter (uncertainty regarding treatment).

It felt so weird (to have the catheter in) and I wasn't sure if it was okay for me to move around. Even just moving my shoulders like this, I thought the tube would snap. So I was in bed for a week like this [places both arms tightly at her sides]. The doctor touched my shoulder and realized it was really stiff...I asked if it was alright if I moved, and he replied "Of course." 


\section{CHILDREN'S IU AND MANAGEMENT}

She also said her parents received "a piece of paper" that had explanation about the treatments written on it, and that she could have taken a look at it but "didn't look." Rather, she'd "wonder what medicine they are injecting" and "what kind of side effects they could cause." (uncertainty regarding treatments).

She also talked a lot about how it took time to get familiar to "living with an IV," how she wasn't able to communicate well with nurses. Including the following statement, it is indicated that she was experiencing uncertainty regarding hospitalization itself.

At the beginning, with so many people I didn't know, I was a bit worried, what my stay in the hospital would be like.

When asked about the uncertainties she experienced, she first mentioned the uncertainty she had about the structure of the hospital, and once again stated that she didn't know how to interact with hospital staff (uncertainty regarding life in hospital). She also said she didn't know why she had to do some of the treatments (uncertainty regarding meaning of a treatment). She also mentioned the following.

Simply, I was anxious about when I could get out, really. The period wasn't exactly fixed, it would change, so I was worried about the progress. Depending on how I was healing, if it wasn't going well the doctor would try a different type of medication, and if that didn't work out either then he would reconsider...And there were actually times that my stay got extended. My pancreas got bad because of a side effect and I was temporarily diabetic... and it pushed back my discharge about a month I think.

This statement implies that she wasn't concerned about the general length of hospitalization that is required, but rather, how things would turn out in her case. In fact, this statement also indicates that she knew well about how her hospitalization period could be affected by her status and how her hospitalization actually got extended due to the status of her pancreas.

Finally, she talked about the concern she had about "money."

I was concerned about the cost of my hospitalization, like how much it cost for a day in bed, or how much a single meal cost. And sometimes there was this special lunch menu where if you apply for...It was a bit of an upgrade from the normal menu, and 


\section{CHILDREN'S IU AND MANAGEMENT}

was offered maybe once a week. And occasionally when I applied for that, I'd get this piece of paper stating the amount I have to pay, the difference from the normal menu, which made me go ahhhhh. It made me wonder, if getting an upgraded menu cost this much, then how much does a normal hospital menu cost?

She wasn't able to ask her family about this for a while. When she and her family participated in another study several years after discharge, they decided to "sort out the fact." This was when she "worked up the courage" and asked, to which they answered by saying insurance and financial assistance from the prefecture covered a lot.

\section{Discussion}

In this study, we investigated what uncertainties children experience now and how they manage them by interviewing six female adolescents who treated their cancer at least once at $\mathrm{Z}$ hospital. As has been theorized and reported in previous research, the participants have experienced various uncertainties regarding their illness and treatment, such as uncertainties regarding the prognosis of the disease, as well as the side effects of the treatments (Mishel, 1988), and the social reaction to the illness (Brashers et al., 2003). On the other hand, as discussed in detail below, some of the uncertainties mentioned in the present interview has not been discussed in previous research. We should also point out that, overall, the amount of uncertainties mentioned in our interview was not a lot, with half the participants saying "none" to the question asking them what uncertainties they experienced.

We will devote this section to the three themes that emerged regarding uncertainties experienced by children: IU related to hospitalization itself, IU with answer / IU without answer, and "why me?" and the two themes that emerged regarding uncertainty management, one concerning the use of role models to reduce IU and the other suggesting a new approach to IU management-uncertainty acceptance.

\section{IU Experienced by Children}

Uncertainties related to hospitalization. Jasmine, who was hospitalized when she was 11 , talked about "uncertainty regarding hospitalization" that is not directly related to 


\section{CHILDREN'S IU AND MANAGEMENT}

illness or treatment. This included uncertainties experienced about the structure of the hospital, how to interact with medical staff, and uncertainties related to hospitalization itself.

Surprisingly, this type of uncertainty hasn't been covered in the context of IU research. In fact, research has not progressed to the point where uncertainties experienced by relatively young children are fully revealed. Most of the surveys considering IU for children target teenage children (Szulczewski et al., 2017), and even when they target younger population, many requires them to answer to existing questionnaires (e.g., Mullins et al., 2007). However, it has long been reported that younger children also experience anxiety and stress due to hospitalization and treatment (e.g., Pearson, 1941). As a related finding, of the 90 children from ages four to six years who were interviewed for hospitalrelated fears, $26 \%$ reported they were scared of being hospitalized and being in the hospital (Salmela, Salanterä, \& Aronen, 2009). The study also reports that a certain number of children are afraid of the hospital's physical environment (buildings and machinery; over $21 \%)$ and unfamiliar people $(10 \%)$. These research findings in the related fields indicate how natural and reasonable it is for Jasmine to have experienced the uncertainties she reported.

It has been pointed out that illness experience is one of the most important experiences in the socialization of children in terms of learning about physical disorders, how to deal with symptoms and medical services (e.g., Mechanic, 1983; Parmelee, 1986). However, from the above findings, if the child has not acquired or is in the process of acquiring knowledge about hospitals and treatments, it is natural that the child would be experiencing uncertainties regarding it in addition to illness and treatment.

IU with answer / IU without answer. As shown above, half of the participants answered "No" to question 2, and those uncertainties articulated seemed to have resolved in a relatively short period of time. This may be because of their sufficient explanation about the illness and the treatment at the $\mathrm{Z}$ hospital. Here, we would like to take particular note of the uncertainties that were experienced even with what seems to be sufficient explanation.

For example, Sarah, who said she was "explained in detail" and thus "knows" about the illness, also said that she had experienced uncertainty about how the surgery would 


\section{CHILDREN'S IU AND MANAGEMENT}

result, when explaining about her illness experience. Kate also said she was well-explained. However, to this day, she said she is still experiencing an uncertainty regarding the possibility of infertility due to the treatment. What these uncertainties have in common is that they are "uncertainties" of "what would happen in my case" that remained even after information about the general possibilities were provided. These narratives indicate that there are critical differences between the objective, scientific, general information and the information regarding "in his or her case." This IU includes, but is not limited to, the IU Stewart (2003) reports as not being able to predict.

In other fields, two types of uncertainty have been distinguished. In medical sociology research, the uncertainty caused by one's incomplete or imperfect mastery of available knowledge, and the uncertainties that stems from the limitations in current medical knowledge is recognized (Fox, 1980). Furthermore, in communication science, Babrow (2001) distinguishes two uncertainties in his problematic integration (PI) theory; epistemological uncertainty and ontological uncertainty. Epistemological uncertainty refers to ways of knowing; it is uncertainty about too much, too little, or inconsistent information, whereas ontological uncertainty refers to uncertainty about "the nature of the world." Matthias (2009) empirically examined the uncertainties experienced by pregnant women based on PI theory and reported that the effective support may differ depending on whether the experienced uncertainties are ontological or epistemological, indicating the possibility that the way to resolve these two types of uncertainties may vary.

However, as can be seen in the definition of IU as "caused by lack of information" (Mishel, 1984), Mishel's and the following studies, which started from studying uncertainties experienced by patients with acute illness, have focused on dealing with IU that can be reduced with sufficient information, in other words, "uncertainties that have answers somewhere." After IU experienced by patients with chronic diseases have also started to get investigated (e.g., Brashers et al. 2003), IU that does not necessarily have an apparent answer, such as the social impact of the illness, have become subject of research. As stated above, Stewart (2003) has also reported that some of the children with cancer acknowledged the inherently unpredictable nature of the illness, pointing out that the 


\section{CHILDREN'S IU AND MANAGEMENT}

unpredictability of the illness could not always be resolved with information and experience. However, it cannot be said that the previous research in IU research has thoroughly examined "IU without answers" and their consequences, implicitly dealing only with "IU about something with information (= answer) somewhere."

Looking at the IU discussed in this study and previous studies, however, it is strongly suggested that patients and their families are experiencing many unanswerable IU, such as uncertainties one might experience even with sufficient objective and scientific information, "Can my illness be cured (not in general terms)?" "What will happen to my future?" (e.g., Hilton, 1994; Madden \& Sim, 2006). Considering the uncertainty of "why me" discussed in the next section, "IU without answer" may be the more fundamental IU experienced by children.

"Why me?": An attempt to expand the concept of IU. Five participants of this study, all except for Mary, talked about the "questioning" of why they had to experience cancer at least once after hearing the diagnosis, saying "why me?" "why did it come to me?"

The word "why," while taking a form of question, may merely express emotions such as strong anger, sadness, and shock rather than one really wanting to know the cause (e.g., Abela, Brozina, \& Haigh, 2002; Katsumata, 2015). However, at least for some individuals who have experienced stressful life events such as illness or injury, it is indicated that the expression "why me?" represents a kind of incomprehension, and that there are processes individuals go through answering to this question. For example, examining the experiences of patients with fibromyalgia, Madden \& Sim (2006) described the process by which patients experience illness as the process of confronting the uncertainty of the cause of the illness, that is, the process of answering the question "why me?" The study suggests that while the biomedical explanation provided at the hospital could be of help to resolve this uncertainty, it isn't enough, and it is an uncertainty for the individual to resolve by finding meanings.

It has also been pointed out that the above-mentioned ontological and epistemological uncertainties have a mutually influential relationship (Diamond-Brown, 


\section{CHILDREN'S IU AND MANAGEMENT}

2016). The uncertainty of "why me," which would be classified as "IU without answer," may also correspond with "IU with answers." For example, Kate said "My classmate's younger brother died of leukemia...I wondered why the illness came to me." Similarly, Melanie said she thought she was "dying" the moment she heard the name of her illness. These participants had leukemia, which has frequently been the subject of TV dramas and movies in Japan, sharing particular (but not always true) images of the treatment method (such as hair loss due to anticancer drug treatment) and prognosis (possibility of death) (e.g., Furuya, 1998; Ono \& Kato, 2020). This may be the reason Kate and Melanie instantly thought of dying the moment they heard the diagnosis.

However, if they had experienced an illness that they had not heard before, they may have experienced "IU without answer," including "why me," only after going through the process of experiencing "IU with answers" about the illness and the treatments, and learning about the illness and the required treatments. In addition, in the case of chronic illnesses, patients may first experience the IU "why me," and only after resolving it and accepting to live with the illness, he or she might shift toward experiencing "IU with answers," regarding how to deal with the illness. On the whole, as most of the participants have experienced it, it is undeniable that "why me" may be an uncertainty that can be experienced relatively typically.

\section{Managing IU}

"Role model" as information to resolve IU. Jasmine experienced IU with regard to the possibility of death when she was diagnosed, and in addition to the explanation from the physicians, the appearance of children who were hospitalized in the ward with the same illness helped resolve this uncertainty. Also, Melanie said that when she was questioning "why me?" she saw other children's positive attitudes and thought "I just gotta do it."

In adult studies, written materials have been used to reduce IU and their effectiveness have been reported (e.g., Zhang, Kwekkeboom, Kim, Loring, \& Wieben, 2020). In the context of other research, the effectiveness of preparation (explanation of the illness and treatment) using visual aids has been suggested as a means of relieving anxiety 


\section{CHILDREN'S IU AND MANAGEMENT}

in children (Brewer, Gleditsch, Syblik, Tietjens, \& Vacik, 2006). In fact, in this study, for example, Melanie mentioned the pamphlet "About Leukemia" distributed by nurses, suggesting that the information obtained there was useful. However, in the case of Jasmine, she could not read the material even if it was "for children" with "illustration" because she was "scared of reading it," and it was the appearance of children in the same ward that helped her resolve IU.

In addition, many have pointed out the effectiveness of peers. Peer support has been shown to have effect in gaining live information and emotional support (e.g, Dunn, Steginga, Rosoman, \& Millichap, 2003). In fact, in recent years, it has been pointed out that not only articles written by specialists but also notes written by people who have experienced the disease or symptom are increasingly referred to online (Fox \& Duggan, 2013). In the present study, Mary said that she was able to talk about hair loss because girls of close age were in the same room, and Melanie also mentioned that she talked about wearing wigs with other girls she shared room with, suggesting the two had benefited from the support they had from peers experiencing similar illnesses and treatment processes.

In contrary to above research, in Jasmine's and Melanie's case, merely the existence of peers, those who were able to overcome a similar adversity, seems to have been informative. This is close to what Rebeiro Gruhl, Lacarte, \& Calixte (2016) depicted as society's mirror, which is listed as one of the essences identified by peer support workers about the service they provide, and in their article, they describe how peer support workers provide "a mirror reflection" to mental health users that recovery is possible, bringing them hope. Nakamura (2002), who also points out that interacting with peers and knowing that "they are not alone" often heals a person, also reported that for a mentally ill person who has continued to "give up," the positively alive figure with the same disability could serve as a role model, having the person feel "I can be like this person."

These episodes and reports demonstrate the informative value peers have that may help one reduce their IU. Especially for young children whose use of written materials is limited and children who gradually become independent from their parents, the information obtained from "the appearance of peers," or a role model, may be particularly crucial. 
Relationship with medical staff and Uncertainty Acceptance. Recent IU research has adopted the complex view of uncertainty (Baxter \& Braithwaite, 2009), conceptualizing it as something that may not always be subject to reduction. For nearly 20 years, influenced by the Uncertainty Reduction Theory proposed by Berger \& Calabresse (1975), research regarding uncertainty in illness has been conducted on the implicit premise that IU should be reduced in order to increase the individual's well-being. This changed after Brashers (2001) made a proposal stating that uncertainty does not necessarily induce anxiety, and as Baxter \& Braithwaite (2009) reports, several uncertainty management theories have been developed in recognition of the fact that people sometimes seek to reduce uncertainty but sometimes not. For example, Brashers \& Hogan (2013), who advocated UMT (uncertainty management theory), theorized how people use information to reduce, maintain, and increase uncertainties.

The data from the present study suggest that reducing, maintaining, and increasing their IU may not necessarily be the only goal people strive to reach in the face of uncertainty. A particularly easy-to-understand example would be Kate's case. Kate, who experienced acute myeloid leukemias twice, said she was experiencing uncertainties about the prognosis and why she had to experience the illness, when she had an interaction with her doctor-in-charge who looked her in the eye and told her he'll do his best. The physician's words did not necessarily have the scientific information that might reduce Kate's IU, however, Kate still says that the conversation with her doctor convinced her that things might turn out okay. In her case, the IU Kate had been experiencing before interacting with the particular doctor became less of a concern after that interaction.

In a recent study that examined specialists' influence on parental uncertainty (Kerr, Harrington, \& Scott, 2019), it is reported that the established confidence and trust between parents and specialists have a great impact on the uncertainty parents experience. Based on the interview conducted on 29 parents who have children with complex chronic illness, Kerr et al. (2019) states that "when parents expressed trust, regardless of whether it was inherent or developed during the visit, their perceptions of the team of specialists as credible directly affected uncertainty, making it less threatening." 


\section{CHILDREN'S IU AND MANAGEMENT}

Kate's case and the report from Kerr et al. (2019) indicates the importance of physicians and specialists, suggesting that the relationship with these medical staff may influence the individual's perception of IU. In both cases, the uncertainties are not reduced with information, nor are they maintained or increased. Rather, as Kerr et al. (2019) put it as "less threatening," the IU simply became less of a threat and concern to the patient and their parents. Considering that the uncertainty hasn't changed but doesn't bother the individual anymore, this phenomenon may be described as uncertainty acceptance, rather than the IU being reduced or managed (Brazhers \& Hogan, 2013).

When considering the acceptance of IU, it should be noted that acceptance is not achieved by information that helps one determine the meaning of an illness-related event, but has a great possibility of being achieved through the relationship with the physician or the specialist. Specifically, in Kate's and Kerr et al.'s cases, meeting and interacting with reliable doctors helped them accept their uncertainties. We still don't know what IU can be accepted, and which medical staff members could play the crucial role. Considering how we have presented IU without answers and how it may be difficult to reduce them by objective information, the idea of acceptance may be of great significance to be examined in the future.

\section{Limitations of the Present Study}

Several limitations of this study are noteworthy. First, we should note here that our data was collected from participants who were able to overcome the difficult, sometimes traumatizing experience enough so that they were able to tell their story to the FA. One potential participant did not contact the FA even after she was given the contact information from her mother. We don't know the reason she decided not to participate; she may not have had the time or maybe she wasn't ready to talk about her experience yet. Thus, we do not believe we have covered all aspects of IU, and our findings may not necessarily be generalizable to female cancer survivors more broadly.

Second, as mentioned above, most of the participants in the present study had leukemia, which is the most famous pediatric cancer in Japan. Unlike other diseases 
(Madden \& Sim, 2006), leukemia has less ambiguity in terms of diagnosis but is a disease that many have created image of it as "moral" and "incurable" (Furuya, 1998). Therefore, there may be completely different findings if different diseases were targeted. Third, the participants were recruited from $\mathrm{Z}$ hospital, which is one of the most prestigious hospitals in Japan. Therefore, even if it wasn't mentioned in the interview, it is very likely that participants had great trust on the hospital and physicians, which may have a significant influence on the uncertainties they experience (Kerr et al., 2019).

\section{Acknowledgments}

We thank the participants involved in this study for taking part.

\section{Declaration of Conflicting Interests}

The authors declared no conflicts of interest with respect to the authorship and/or publication of this article.

\section{Funding}

The authors disclosed receipt of the following financial support for the research, authorship, and/or publication of this article: This work was supported by the JSPS KAKENHI $[15 \mathrm{~J} 12105]$. 


\section{CHILDREN'S IU AND MANAGEMENT}

\section{References}

Abela, J. R. Z., Brozina, K., \& Haigh, E. P. (2002). An examination of the response styles theory of depression in third- and seventh-grade children: A short-term longitudinal study. Journal of Abnormal Child Psychology, 30, 515-527.

https://doi.org/10.1023/A:1019873015594

Andriessen, I., Phalet, K., \& Lens, W. (2006). Future goal setting, task motivation and learning of minority and non-minority students in Dutch schools. The British Journal of Educational Psychology, 76, 827-850. https://doi.org/10.1348/000709906X148150

Babrow, B. A. S. (2001). Uncertainty, value, communication, and problematic integration. Journal of Communication, 51, 553-573.

Brashers, D. E., Neidig, J. L., Russell, J. A., Cardillo, L. W., Haas, S. M., Dobbs, L. K., ... Nemeth, S. (2003). The medical, personal, and social causes of uncertainty in HIV illness. Issues in Mental Health Nursing, 24, 497-522. https://doi.org/10.1080/01612840390207962

Clayton, M. F., Mishel, M. H., \& Belyea, M. (2006). Testing a Model of Symptoms, Communication, Uncertainty, and Well-Being, in Older Breast Cancer Survivors. Research in Nursing \& Health, 29, 18-39. https://doi.org/10.1002/nur

Cross, S. E., \& Markus, H. R. (1994). Self-schemas, possible selves , and competent performance. Journal of Educational Psychology, 86, 423-438.

Diamond-Brown, L. (2016). The doctor-patient relationship as a toolkit for uncertain clinical decisions. Social Science and Medicine, 159, 108-115.

https://doi.org/10.1016/j.socscimed.2016.05.002

Dunn, J., Steginga, S. K., Rosoman, N., \& Millichap, D. (2003). A review of peer support in the context of cancer. Journal of Psychosocial Oncology, 21, 55-67. https://doi.org/10.1300/J077v21n02

Elo, S., \& Kyngäs, H. (2008). The qualitative content analysis process. Journal of Advanced Nursing, 62, 107-115. https://doi.org/10.1111/j.1365-2648.2007.04569.x

Fox, R. C. (1980). The evolution of medical uncertainty. Milbank Memorial Fund Quarterly, Health and Society, 58, 1-49. 


\section{CHILDREN'S IU AND MANAGEMENT}

Fox, S., \& Duggan, M. (2013). Health Online 2013. Retrieved from https://www.pewinternet.org/wp- content/uploads/sites/9/media/ Files/Reports/PIP HealthOnline.pdf (Archived by WebCite ${ }^{\circledR}$ at https://www.webcitation.org/74sbsnhYG) Furuya, K. (1998). 健康な小児が抱くがん白血病のイメージについて. [ A study of the images of cancer and leukemia in healthy children]. Journal of Chiba Academy of Nursing Science, 4, 39-46.

Giurgescu, C., Penckofer, S., Maurer, M. C., \& Bryant, F. B. (2006). Impact of uncertainty, social support, and prenatal coping on the psychological well-being of high-risk pregnant women. Nursing Research, 55(5), 356-365. Retrieved from http://www.ncbi.nlm.nih.gov/pubmed/16980836

Han, P. K. J., Klein, W. M. P., \& Arora, N. K. (2011). Varieties of uncertainty in health care: A conceptual taxonomy. Medical Decision Making, 31, 828-838. https://doi.org/10.1177/0272989X10393976

Hilton, B. A. (1994). The uncertainty stress scale :Its development and psychometric properties. Canadian Journal of Nursing Research, 26, 15-30.

Hommel, K. a., Chaney, J. M., Wagner, J. L., White, M. M., Hoff, A. L., \& Mullins, L. L. (2003). Anxiety and depression in older adolescents with long-standing asthma: The role of illness uncertainty. Children's Health Care, 32, 51-63. https://doi.org/10.1207/S15326888CHC3201_4

Hsieh, H. F., \& Shannon, S. E. (2005). Three approaches to qualitative content analysis. Qualitative Health Research, 15, 1277-1288. doi.org/10.1177/1049732305276687

Husman, J., \& Shell, D. F. (2008). Beliefs and perceptions about the future: A measurement of future time perspective. Learning and Individual Differences, 18, 166-175. Retrieved from http://ac.els-cdn.com/S1041608007001148/1-s2.0-S1041608007001148main.pdf?_tid=b2bd3226-0f01-11e4-b18700000aab0f26\&acdnat=1405746249_fdc4b3012be1deb4f12db622d57b462e

Ishii, Y. (2018). 小巟慢性疾患経験者にみるイルネス・アンサーテンティの発達的影 響 : 成人期における将来展望との関連に着目して.[The developmental effect of illness uncertainty in young adults with early-onset chronic diseases]. Japanese Journal 


\section{CHILDREN'S IU AND MANAGEMENT}

of Qualitative Psychology, 18, 217-241. doi.org/10.24525/jaqp.18.1_217

Katsumata, Y. (2015). 自己への怒りが反忽と精神的健康に及ぼす影響. [The effects of self-anger on rumination and on mental health]. Japanese Journal of Psychology, 86, 313-322. doi.org/10.4992/jjpsy.86.14049

Kerr, A. M., Harrington, N. G., \& Scott, A. M. (2019). Communication and the appraisal of uncertainty: Exploring parents' communication with credible authorities in the context of chronic childhood illness. Health Communication, 34, 201-211. https://doi.org/10.1080/10410236.2017.1399508

Lewin, K. (1942) Time perspective and morale. New York: Houghton Mifflin.

Madden, S., \& Sim, J. (2006). Creating meaning in fibromyalgia syndrome. Social Science and Medicine, 63, 2962-2973. https://doi.org/10.1016/j.socscimed.2006.06.020

Markus, H. (1983). Self-knowledge : An expanded view. Journal of Personality, 51, 543-565.

Matthias, M. S. (2009). Problematic integration in pregnancy and childbirth: Contrasting approaches to uncertainty and desire in obstetric and midwifery care. Health Communication, 24, 60-70. https://doi.org/10.1080/10410230802607008

Mechanic, D. (1983). Adolescent health and illness behavior: Review of the literature and a new hypothesis for the study of stress. Journal of Human Stress, 9, 12-13. https://doi.org/10.1080/0097840X.1983.9936119

Merriam, S. B. (1998). Qualitative research and case study applications in education. Revised and expanded from" Case study research in education.". San Francisco: Jossey-Bass Publishers.

Mishel, MH. (1984). Perceived uncertainty and stress in illness. Research in Nursing \& Health, 7, 163-171. Retrieved from http://www.ncbi.nlm.nih.gov/pubmed/6567948

Mishel, MH. (1988). Uncertainty in illness. Journal of Nursing Scholarship, 20, 225-232.

Mishel, MH. (1997). Uncertainty in Illness Scales manual. Chapel Hill: University of North Carolina.

Mullins, L. L., Wolfe-Christensen, C., Pai, A. L. H., Carpentier, M. Y., Gillaspy, S., Cheek, J., \& Page, M. (2007). The relationship of parental overprotection, perceived child vulnerability, and parenting stress to uncertainty in youth with chronic illness. Journal 


\section{CHILDREN'S IU AND MANAGEMENT}

of Pediatric Psychology, 32(8), 973-982. https://doi.org/10.1093/jpepsy/jsm044

Nakamura, K. (2002). 精神障害をもつ人のピアカウンセリング研究(2). [A study on peer counseling for mentally disabled persons (2)]. Journal of Chikushi Jogakuen University, 14, 255-273. http://id.nii.ac.jp/1219/00000866/

Northouse, L. L., Dorris, G., \& Charron-Moore, C. (1995). Factors affecting couples' adjustment to recurrent breast cancer. Social Science \& Medicine, 41, 69-76. Retrieved from http://www.ncbi.nlm.nih.gov/pubmed/7667674

Nuttin, J. \& Lens, W. (1985). Future time perspective and motivation: Theory and research method. Leuven: Leuven University Press.

Oettingen, G., \& Mayer, D. (2002). The motivating function of thinking about the future: Expectations versus fantasies. Journal of Personality and Social Psychology, 83, 11981212. https://doi.org/10.1037//0022-3514.83.5.1198

Omata, T. (2018). 長期フォローアップに求める支援〜小巟がん患者からのシフトチェ ンジ. [Support needed in long-term follow up: Shift change from being a child patient]. The Japanese Journal of Pediatric Hematology/Oncology, 55, 393-397. doi.org/10.11412/jspho.55.393

Ono, N., \& Kato, M. (2020). A content analysis of Japanese cancer documentaries across 25 years. Cogent Arts and Humanities, 7(1). doi.org/10.1080/23311983.2020.1801116

Pai, A. L. H., Mullins, L. L., Drotar, D., Burant, C., Wagner, J., \& Chaney, J. M. (2007). Exploratory and confirmatory factor analysis of the child uncertainty in illness scale among children with chronic illness. Journal of Pediatric Psychology, 32, 288-296.

Parmelee, A. H. (1986). Children's illnesses: Their beneficial effects on behavioral development. Child Development, 57, 1-10. https://doi.org/10.1111/j.14678624.1986.tb00001.x

Pearson, G. H. J. (1941). Effect of operative procedures on the emotional life of the child. American Journal of Diseases of Children, 62, 716-729.

Rebeiro Gruhl, K. L., Lacarte, S., \& Calixte, S. (2016). Authentic peer support work: Challenges and opportunities for an evolving occupation. Journal of Mental Health, 25, 78-86. https://doi.org/10.3109/09638237.2015.1057322 


\section{CHILDREN'S IU AND MANAGEMENT}

Salmela, M., Salanterä, S., \& Aronen, E. (2009). Child-reported hospital fears in 4 to 6-yearold children. Pediatric Nursing, 35, 269-276, 303. Retrieved from http://www.ncbi.nlm.nih.gov/pubmed/21143264

Sammarco, A. (2001). Perceived social support, uncertainty, and quality of life of younger breast cancer survivors. Cancer Nursing, 24, 212-219.

Stewart, J. L. (2003). "Getting used to it": Children finding the ordinary and routine in the uncertain context of cancer. Qualitative Health Research, 13, 394-407. https://doi.org/10.1177/1049732302250336

Stewart, J. L., Lynn, M. R., \& Mishel, M. H. (2010). Psychometric evaluation of a new instrument to measure uncertainty in children with cancer. Nursing Research, 59, 119 126. https://doi.org/10.1097/NNR.0b013e3181d1a8d5.Psychometric

Szulczewski, L., Mullins, L. L., Bidwell, S. L., Eddington, A. R., \& Pai, A. L. H. (2017). Meta-Analysis: Caregiver and Youth Uncertainty in Pediatric Chronic Illness. Journal of Pediatric Psychology, 42(4), 395-421. https://doi.org/10.1093/jpepsy/jsw097

Takahashi, H., Kajiwara, R., Kato, M., Hasegawa, D., Tomizawa, D., Noguchi, Y., ... \& Ohara, A. (2018). Treatment outcome of children with acute lymphoblastic leukemia: the Tokyo Children's Cancer Study Group (TCCSG) Study L04-16. International journal of hematology, 108, 98-108.

White, M. M., Chaney, J. M., Mullins, L. L., Wagner, J. L., Hommel, K. a., Andrews, N. R., \& Jarvis, J. N. (2005). Children's perceived illness uncertainty as a moderator in the parent-child distress relation in juvenile rheumatic diseases. Rehabilitation Psychology, 50, 224-231. https://doi.org/10.1037/0090-5550.50.3.224

Zhang, Y., Kwekkeboom, K., Kim, K. S., Loring, S., \& Wieben, A. M. (2020). Systematic review and meta-analysis of psychosocial uncertainty management interventions. Nursing Research, 69, 3-12. https://doi.org/10.1097/NNR.0000000000000368 